\title{
Jogos educacionais
}

\author{
Liane Margarida Rockenbach Tarouco \\ Letícia Coelho Roland \\ Marie-Christine Julie Mascarenhas Fabre \\ Mary Lúcia Pedroso Konrath
}

Resumo

O presente artigo tem por objetivo discutir sobre a importância da utilização de jogos educacionais na educação, como forma de motivação do aluno. Além disso, abordaremos a tecnologia Flash e a utilização da ferramenta de autoria Macromedia Flash MX no desenvolvimento de jogos educacionais.

Palavras-chave: jogos educacionais, Macromedia Flash MX

\section{Computador na Educação}

A importância do uso dos computadores e das novas tecnologias na educação deve-se hoje não somente ao impacto desta ferramenta na nossa sociedade e às novas exigências sociais e culturais que se impõe, mas também ao surgimento da Tecnologia Educativa. Eles começaram a ser utilizados no contexto educativo a partir do rompimento com o paradigma tradicional e surgimento do construtivismo, que enfatiza a participação e experimentação do sujeito na construção de seu próprio conhecimento, através de suas interações. Com isso a capacidade do professor e o conteúdo dos livros constituem uma condição necessária mas não suficiente para garantir a aprendizagem, pois ela envolve um processo de assimilação e construção de conhecimentos e habilidades, de natureza individual e intransferível.

Os efeitos do computador na escola dependem de diversos fatores, contudo a generalidade da investigação aponta para a possibilidade de desenvolvimento de novas competências cognitivas, entre elas: maior responsabilidade dos alunos pelo trabalho, novos laços de entre-ajuda e novas relações professor-aluno. Assim, o computador se constitui numa ferramenta poderosa, que pode (e deve) ter todas as suas potencialidades utilizadas com propósitos educacionais, proporcionando ao professor a possibilidade de enriquecer sua prática pedagógica com recursos multimídia, tais como jogos educacionais, vídeos, animações, gráficos e outros materiais que possibilitem ao aluno aprender de forma prazerosa, cativante, divertida e motivadora.

Neste sentido, os jogos educacionais podem ser um elemento catalisador, capaz de contribuir para o "processo de resgate do interesse do aprendiz, na tentativa de melhorar sua vinculação afetiva com as situações de aprendizagem" (Barbosa, 1998). A vinculação afetiva exerce um papel fundamental, pois, cansado de muitas vezes tentar e não alcançar resultados satisfatórios no chamado "tempo" da escola, o aluno experimenta sentimentos de insatisfação constantes os quais funcionam como bloqueadores nos avanços qualitativos de aprendizagem.

\section{Jogos educacionais}

De uma forma geral, os jogos fazem parte da nossa vida desde os tempos mais remotos, estando presentes não só na infância, mas como em outros momentos. Os jogos podem 
ser ferramentas instrucionais eficientes, pois eles divertem enquanto motivam, facilitam o aprendizado e aumentam a capacidade de retenção do que foi ensinado, exercitando as funções mentais e intelectuais do jogador.

Além disso, também permitem o reconhecimento e entendimento de regras, identificação dos contextos que elas estão sendo utilizadas e invenção de novos contextos para a modificação das mesmas. Jogar é participar do mundo de faz de conta, dispor-se às incertezas e enfrentar desafios em busca de entretenimento. Através do jogo se revelam a autonomia, criatividade, originalidade e a possibilidade de simular e experimentar situações perigosas e proibidas no nosso cotidiano.

Quando motivadores do processo de aprendizagem, eles podem ser definidos como jogos educacionais. Contudo, há ainda muita discussão sobre o que são jogos educacionais. Dempsey, Rasmussem e Luccassen (1996) citados por Botelho (2004) definem que os jogos educacionais "se constituem por qualquer atividade de formato instrucional ou de aprendizagem que envolva competição e que seja regulada por regras e restrições". Nesse sentido, no intuito de analisar jogos educacionais computadorizados, aqui tomamos como jogos educacionais todas aquelas aplicações que puderem ser utilizadas para algum objetivo educacional ou estiverem pedagogicamente embasadas.

Todavia, é importante ressaltar a idéia de que o uso de recursos tecnológicos, dentre eles o jogo educacional, não pode ser feito sem um conhecimento prévio do mesmo e que esse conhecimento deve sempre estar atrelado a princípios teórico-metodológicos claros e bem fundamentado. Daí a importância dos professores dominarem as tecnologias e fazerem uma análise cuidadosa e criteriosa dos materiais a serem utilizados, tendo em vista os objetivos que se quer alcançar.

Existem diferentes tipos de jogos, que são classificados de acordo com seus objetivos, tais como jogos de ação, aventura, cassino, lógicos, estratégicos, esportivos, roleplaying games (RPGs), entre outros. Alguns desses tipos podem ser utilizados com propósitos educacionais, conforme destacamos:

Ação - os jogos de ação podem auxiliar no desenvolvimento psicomotor da criança, desenvolvendo reflexos, coordenação olho-mão e auxiliando no processo de pensamento rápido frente a uma situação inesperada. $\mathrm{Na}$ perspectiva instrucional, o ideal é que o jogo alterne momentos de atividade cognitiva mais intensa com períodos de utilização de habilidades motoras.

Aventura - os jogos de aventura se caracterizam pelo controle, por parte do usuário, do ambiente a ser descoberto. Quando bem modelado pedagogicamente, pode auxiliar na simulação de atividades impossíveis de serem vivenciadas em sala de aula, tais como um desastre ecológico ou um experimento químico.

Lógico - os jogos lógicos, por definição, desafiam muito mais a mente do que os reflexos. Contudo, muitos jogos lógicos são temporalizados, oferecendo um limite de tempo dentro do qual o usuário deve finalizar a tarefa. Aqui podem ser incluídos clássicos como xadrez e damas, bem como simples caça-palavras, palavras-cruzadas e jogos que exigem resoluções mateméticas. 
Role-playing game (RPG) - Um RPG é um jogo em que o usuário controla um personagem em um ambiente. Nesse ambiente, seu personagem encontra outros personagens e com eles interage. Dependendo das ações e escolhas do usuário, os atributos dos personagens podem ir se alterando, construindo dinamicamente uma história. Esse tipo de jogo é complexo e difícil de desenvolver. Porém, se fosse desenvolvido e aplicado à instrução, poderia oferecer um ambiente cativante e motivador.

Estratégicos - os jogos estratégicos se focam na sabedoria e habilidades de negócios do usuário, principalmente no que tange à construção ou administração de algo. Esse tipo de jogo pode proporcionar uma simulação em que o usuário aplica conhecimentos adquiridos em sala de aula, percebendo uma forma prática de aplicá-los.

Independente do tipo dos jogos, eles podem ser utilizados de diferentes formas, conforme destaca Botelho (2004):

[...] para treinamento de habilidades operacionais, conscientização e reforço motivacional, desenvolvimento de insight e percepção, treinamento em comunicação e cooperação, integração e aplicação prática de conceitos aprendidos e até mesmo assessment (avaliação de aprendizagem).

\section{Jogos educacionais no computador}

A utilização de jogos computadorizados na educação proporciona ao aluno motivação, desenvolvendo também hábitos de persistência no desenvolvimento de desafios e tarefas. Os jogos, sob a ótica de crianças e adolescentes, se constituem a maneira mais divertida de aprender. Além disso, eles proporcionam a melhora da flexibilidade cognitiva, pois funcionam como uma ginástica mental, aumentando a rede de conexões neurais e alterando o fluxo sanguíneo no cérebro quando em estado de concentração.

Os jogos educacionais se baseiam numa abordagem auto-dirigida, isto é, aquela em que o sujeito aprende por si só, através da descoberta de relações e da interação com o software. Neste cenário, o professor tem o papel de moderador, mediador do processo, dando orientações e selecionando softwares adequados e condizentes com sua prática pedagógica. Ele vai além do simples coletor de informações, ele precisa pesquisar, selecionar, elaborar e confrontar visões, metodologias e os resultados esperados.

Existem hoje no mercado uma gama de jogos para ensinar conceitos difíceis de serem assimilados pelo fato de não existirem aplicações práticas mais imediatas, como o conceito de eletrização, conservação de energia, trigonometria, grandes navegações, entre outros. Entretanto, o nosso grande desafio é apoiar o aluno para que sua atenção não seja desviada somente para a competição, deixando de lado os conceitos a serem desenvolvidos. Por isso, a reflexão do aluno e a observação do professor são fatores essenciais quando utilizamos jogos educacionais em sala de aula com fins pedagógicos.

\section{Jogos na Web}

O crescimento e a popularização da Internet vem tornando possível utilizar novas estratégias e ferramentas para apoiar o processo de ensino aprendizagem. Entre elas, 
temos os jogos educacionais via Web que possibilitam aprendizagem assíncrona, agregação e processamento dos dados, interação em tempo real através de uma população geograficamente dispersa e um cenário dinâmico.

Os jogos interativos na Web não são apenas para brincadeira. Com a grande aceitação da Internet e com a chegada de Plug-Ins de Multimídia para Browsers, atualmente muitos professores estão usando jogos baseados na Web como uma forma de empregar, simular, educar e assessorar. Contudo, com toda informação entregue pela Web, reduzir a latência é um ponto crítico. Também se deve ter um cuidado com a motivação, que pode diminuir rapidamente se um estudante está esperando pela resposta do jogo, ou mais informações para download. Respostas rápidas num jogo são cruciais.

A utilização desses novos recursos modifica a dinâmica do ensino, as estratégias e o comprometimento de alunos e professores. Com esses novos recursos e ferramentas a educação pode ensejar uma aprendizagem significativa, proporcionando que o aluno aprenda de forma dinâmica e motivadora. Os avanços das tecnologias de softwares e linguagens de autoria facilitaram o processo de construção de jogos educacionais, fazendo com que professores possam passar de meros expectadores e avaliadores para produtores de jogos educacionais, capacitando-se para isso e podendo produzir softwares de qualidade, contextualizados com a sua realidade.

\section{Desenvolvimento de jogos educacionais}

Para o desenvolvimento de jogos educacionais é preciso pensar um tema a ser proposto, quais os objetivos a serem alcançados e de que forma vamos organizar este material. Precisamos também escolher e produzir imagens, além de selecionar mídias a serem utilizadas no projeto. Depois de fazer o planejamento, partimos para o desenvolvimento do jogo através de uma linguagem de autoria propriamente dita.

Atualmente, existe no mercado mundial, um software que, por sua flexibilidade e baixo grau de complexidade, vem se constituindo como um grande aliado no desenvolvimento de jogos educacionais, o Macromedia Flash MX. Este software oferece uma interface que agrega diversas necessidades do desenvolvedor de jogos, como criação de recursos gráficos, entre eles imagens .gif e .jpg, e filmes animados no formato .swf; importação de arquivos externos, tais como vídeo e aúdio, criados ou editados em outros softwares.

Além disso, o Flash MX também se configura como uma excelente ferramenta de autoria, pois com ele podemos desenvolver desde um simples jogo-da-velha até um complexo jogo multi-usuário em tempo real. Isso porque ele disponibiliza um ambiente de desenvolvimento da linguagem ActionScript, que traz os recursos e funcionalidades de uma linguagem de programação bem consistente. Assim, Makar (2002) entende que uma das maiores vantagens desta ferramenta está exatamente em reunir diversas funcionalidades em um único software: ferramenta de animação, programa de criação de Websites, programa de desenvolvimento de aplicações e, mais recentemente, plataforma de desenvolvimento de jogos.

Ainda podemos destacar outras vantagens, que fizeram do Flash MX um dos softwares mais utilizados e de maior aceitação entre os usuários nos últimos anos. Considerandose que ele foi projetado para ser visualizado em páginas da Web, é, com certeza a 
melhor escolha para desenvolvimento de material a ser disponibilizado na rede. A tecnologia Flash faz uso de vetores gráficos e compressão de arquivos de som, o que faz com que o tamanho final dos arquivos seja muito pequeno quando comparado àqueles criados em outros softwares. No desenvolvimento de um jogo, onde os recursos multimídia são largamente utilizados, essas características já se configuram numa grande vantagem em relação a outros softwares disponíveis.

Um jogo educacional, voltado para crianças de 6 a 8 anos, foi desenvolvido por pesquisadores do Centro Interdisciplinar de Novas Tecnologias na Educação para uso de professores e alunos do Pós-Graduação em Informática na Educação (Doutorado), Especialização a distância em Informática na Educação e Mestrado a Distância da Universidade Federal do Rio Grande do Sul. Esse jogo, simples e de fácil desenvolvimento, chamado Caldeirão da Bruxa, propõe a nomeação de objetos do nosso cotidiano pelas crianças, conforme mostra sua tela inicial, na figura 1.

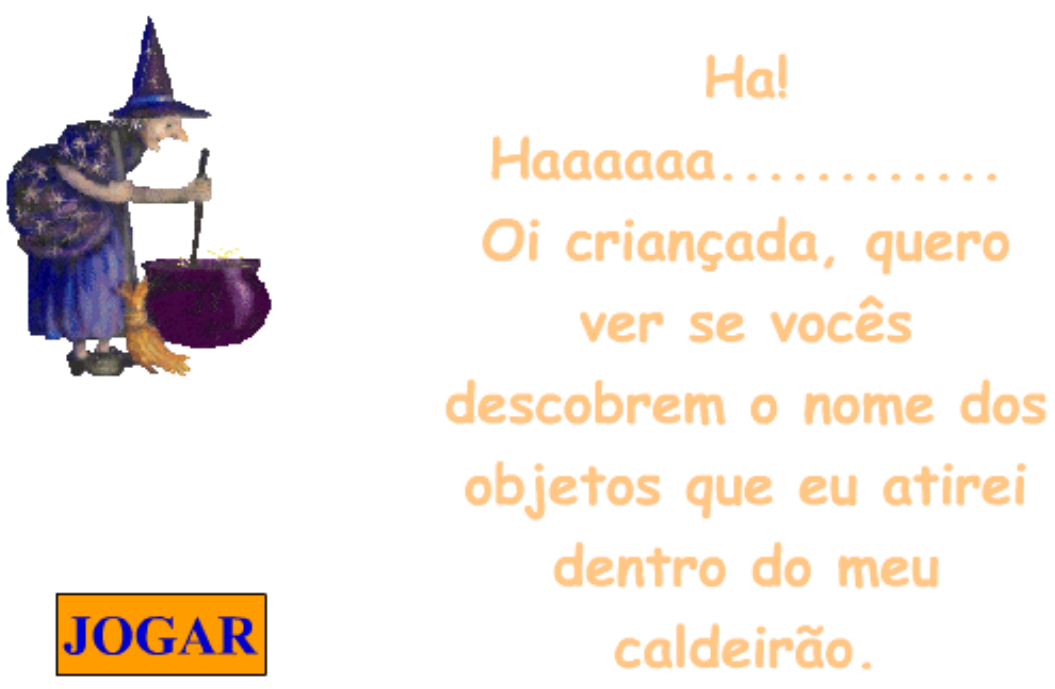

Figura 1 - Caldeirão da Bruxa

\section{Alguns jogos educacionais analisados}

Através de pesquisas realizadas pelo grupo de pesquisadores do Centro Interdisciplinar de Novas Tecnologias na Educação analisamos jogos educacionais. Aqui apresentaremos algumas análises e considerações a cerca de dois softwares existentes nos mercados e utilizados por professores da educação infantil e ensino fundamental. Os jogos analisados foram: Betsy goes to preschool (figura 2) e Supermercado (figura 3).

O software Betsy goes to preeschol é um jogo educativo, que apresenta em sua interface, uma tela chamada de Área de Recreio Virtual 3D, na qual o aluno clicando em um dos cinco objetos da tela, pode fazer atividades com números, letras, figuras, centro de jogos (Memória, Quebra-cabeças e a Máquina de Filmes) e Ronaldinho 
Toupeira. O software possui na janela de seleção inicial as seguintes opções: Brincar com Betsy, Seção de Adultos e Manual Eletrônico.

Na seção de adultos, você pode escolher as alternativas: Brincar com Betsy, Guia para pais e professores, Mudar de idioma e Escrivaninha do Diretor, este último se subdivide em: Preferências do Jogador, Atuação do jogador, Criar jogador, Eliminar jogador ou Escolher Apresentação. Ele é um jogo que tem como principal objetivo a fixação e memorização de determinado conteúdo: reconhecimento e discriminação de figuras e raciocínio-lógico para crianças pequenas. Tem como característica ser um jogo fechado e com enfoque algorítmico, pois apesar dele apresentar múltiplas opções de atividades, após ser escolhida uma, o aluno só pode fazer aquilo que o programa determinar.

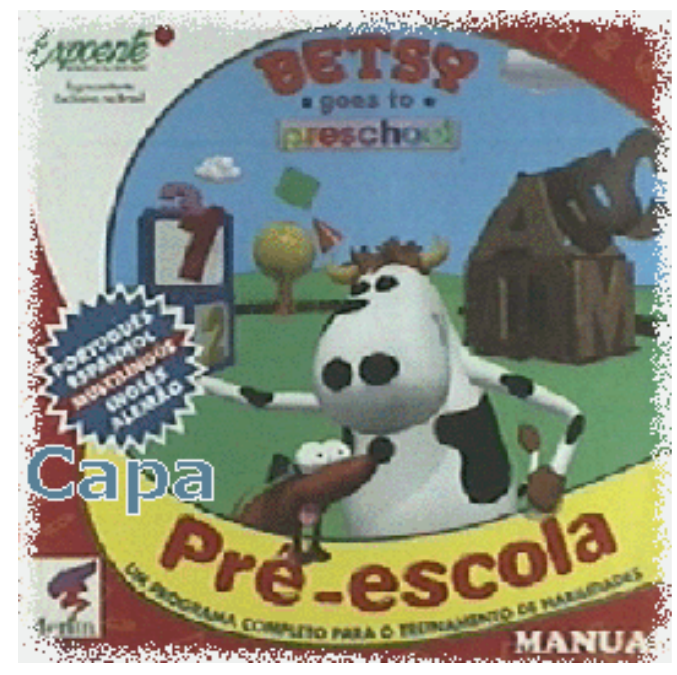

Figura 2 - jogo educacional em português - espanhol- inglês e alemão - versão 1.0 Fabricado por Merlin Interactive Systems e distribuido por Expoente.

O jogo Supermercado é um "ambiente virtual" no qual os alunos vivenciam situações de compra e venda. Ele propicia a aprendizagem das 4 operações básicas de matemática, Número inteiros, Números decimais, Frações, Proporcionalidade, Medidas, Orientação espacial, Figuras planas e sólidos geométricos. Essas situações de aprendizagens acontecem dentro de um ambiente lúdico que simula um Supermercado, no qual o aluno pode: Fazer passeios, fazer compras, comprar com suas economias e ser o caixa.

$\mathrm{O}$ software permite ainda que pais e professores montem um roteiro de compras e personalizem o jogo. Já para a criança, ele permite que ela imprima, monte e brinque com o dinheiro e produtos que aparecem no jogo. Ele é um Jogo educativo que envolve conteúdos pedagógicos de Matemática que acontecem em um Supermercado. È um software aberto, heurístico que apresenta múltiplas opções de atividades nas quais o aluno vivencia situações reais de uso da Matemática, deparando-se com um leque de "situações-problemas" os quais lhe permitem construir mais facilmente os conceitos vivenciados no dia-a-dia e também na escola. 


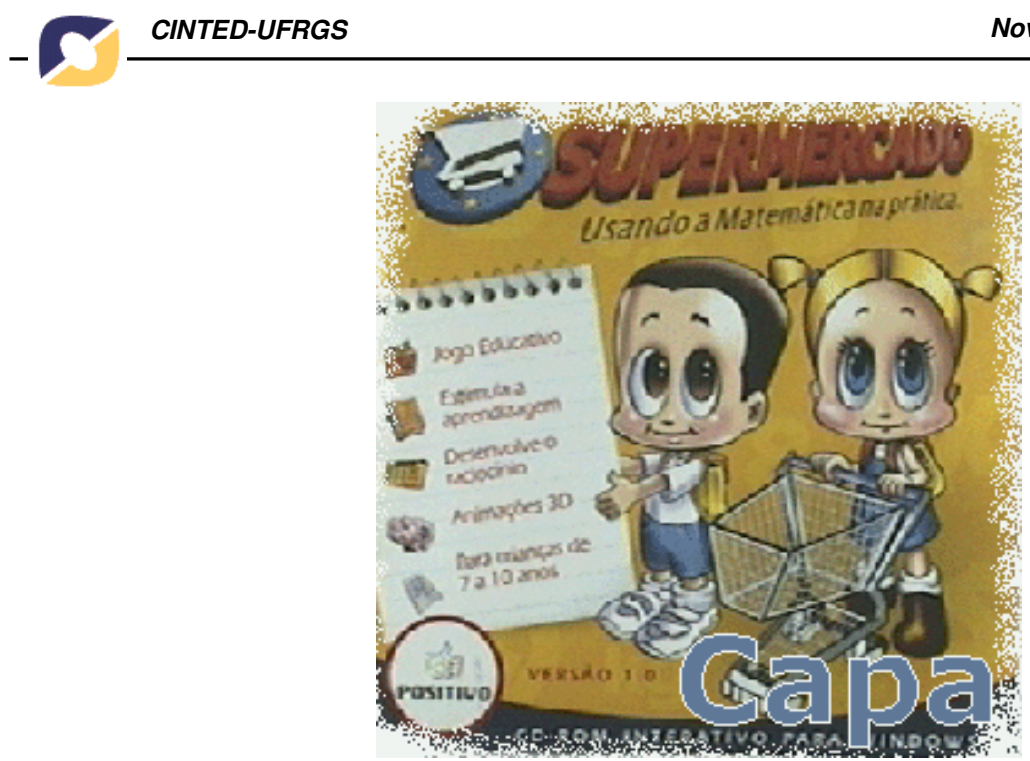

Figura 3 - Jogo educacional em português - versão 1.0 - Fabricado por Sonopress Indústria e Comércio Fonográfica Ltda. Distribuido por Positivo Informática.

\section{Conclusão}

Com as mudanças no paradigma pedagógico e o surgimento das novas tecnologias, tais como o computador e a Internet, os professores abriram as portas ao uso de recursos que extrapolam a visão tradicional e os métodos meramente discursivos no processo de ensino-aprendizagem. Assim, com o crescimento da Tecnologia Educativa, os jogos educacionais se configuraram como uma ferramenta complementar na construção e fixação de conceitos desenvolvidos em sala de aula, bem como num recurso motivador tanto para o professor como para o aluno.

O surgimento de softwares de fácil utilização, como o Macromedia Flash MX, que cria um arquivo pequeno e ideal para a visualização via Web, faz com que professores e pedagogos se interessem pelo desenvolvimento de jogos educacionais, tirando esse encargo das mãos de programadores, como vinha ocorrendo até então. Assim, acreditase que, aos poucos, esse tipo de software educacional disponível no mercado terá sua qualidade aumentada, no que diz respeito ao seu caráter pedagógico.

\section{Referências}

BARBOSA, Laura Monte Serrat. Projeto de trabalho: uma forma de atuação psicopedagógica. 2.ed. Curitiba: L. M. S, 1998.

BOTELHO, Luiz. Jogos educacionais aplicados ao e-learning. Disponível em: $<$ http://www.elearningbrasil.com.br/news/artigos/artigo_48.asp. $>$ Acessado em: janeiro de 2004.

MAKAR, Jobe. MacromediaFlash MX Game Design Demystified: The Official Guide to Creating Games with Flash. Berkeley, CA: Peachpit Press, 2002. 